\title{
Grisey, Gérard
}

\section{Geb. 17. 6. 1946 in Belfort (Frankreich); \\ gest. 11. 11. 1998 in Paris}

Im Eröffnungskonzert der Donaueschinger Musiktage 1978 begegneten die meisten deutschen Hörer dem Namen und der Musik des jungen Franzosen wohl zum ersten Mal. Doch hinterließ die Uraufführung des Werkes Sortie vers la lumière $d u$ jour ("... eine Klangkonstruktion, die immer dichter wird, immer mehr Schichten umfaßt, eine Kurve wie die Sonne beschreibt«, so der Kritiker Heinz W. Koch) laut Presseecho keine nachhaltige Wirkung. Auch das Studium des ausführlichen Einführungstextes beschrieb keine einprägsame programmatische Idee, sondern eher ein grundsätzliches Credo: "Die verschiedenen Prozesse, die bei der Veränderung eines Klanges in einen anderen oder einer Klanggruppe in eine andere auftreten, bilden die eigentliche Basis meiner Schreibweise, die Idee und den Keim jeder Komposition." Und später: "In meiner Musik läßt sich der Klang niemals für sich selbst betrachten; er ist immer durch den Filter seiner Geschichte gegangen. Wohin geht er, Woher kommt er? Diese Frage stelle ich mir in jedem Augenblick, bei jeder Partitur, die ich gerade schreibe." Erst nach Darlegung dieses übergeordneten Ansatzes unmittelbar aus dem Klangmaterial heraus kam der Komponist auf die zwei verschmelzenden Prozesse der Partitur zu sprechen ( $» .$. des Lichts, charakterisiert durch harmonische Teiltöne, und den des Schattens, charakterisiert durch unharmonische Teiltöne und weißes Rauschen (), deutete er nur knapp einen Bezug zu einer Bildvorstellung (»... wie die Barke des Sonnengottes Râ am Himmel«) und zur Textquelle des Titels an (altägyptisches Totenbuch).

Bereits fünf Jahre zuvor, im Jahr 1973, hatte sich Gr. mit Gleichgesinnten aus Messiaens Klasse am Pariser Conservatoire - Hugues Dufourt, $\mathrm{Mu}$ rail, Levinas u. a. - zur lockeren Gruppe »L'Itinéraire" zusammengeschlossen. Man war sich einig in der Abkehr von allen nur von außen an die Musik herangetragenen Konstrukten und Ideen, einig in der Rückbesinnung auf die natürlichen Gegebenheiten des Oberton-Spektrums und die reichen Möglichkeiten seiner Entfaltung und Verwandlung. "Wir sind Musiker und unser Modell ist der Klang und nicht die Literatur ...«, wird Gr. während der Darmstädter Ferienkurse 1982 feststellen, die eine umfassende Präsentation der ItinéraireMitglieder, ihrer Musik und ihrer Ensembles brachten (vgl. Wilson, 33). Zu diesem Zeitpunkt war Gr.s Komposition Partiels ("Teiltöne«) mit seinen organisch wuchernden Netzstrukturen bereits aufmerksam zur Kenntnis genommen worden und hatte der Gruppe gar das Etikett "partielistes« eingebracht. Es lag auch bereits der komplette Zyklus Les espaces acoustiques (Die akustischen Räume; 1974-81) vor, der ein kontinuierlich screscendierendes ( und dann ein wenig an Boulez' ursprüngliches Mallarmé-Porträt »Pli selon pli» erinnerndes) Instrumentarium vorsieht und als dessen Herzstück Partiels figuriert, 1. Prologue (Bratsche, Live-Elektronik), 2. Périodes (sieben Spieler), 3. Partiels (16 bzw. 18 Spieler), 4. Modulations (33 Spieler), 5. Transitoires (großes Orchester).

Bei der Durchsicht von Gr.s Werkliste fällt auf, $\mathrm{da} ß$ die Singstimme und damit die Textvertonung einen relativ geringen Stellenwert besitzt. Von $\mathrm{Be}$ deutung ist, daß Gr. und seine Freunde sich nicht auf einen verschwommenen, von fragwürdiger Nostalgie belasteten Begriff von Natur und Naturklang berufen, sondern ihre Spektralstudien mit dem Wissen und der Objektivität von Toningenieuren betreiben. Gefahren liegen für die Gruppe L'Itinéraire insgesamt sicherlich in einer gewissen Einseitigkeit des Recherchierens. Andererseits mag gerade der fortwährende Gedankenaustausch unter so verschiedenartigen Temperamenten vor gestalterischer Monotonie oder gar schöpferischem Stillstand bewahren.

Noten: Ricordi (Mailand).

Dokumente: Werkeinführung »Une sortie vers la lumière du jour«, Programmheft Donaueschinger Musiktage 1978, 8-10.

Literatur: WILson, P. N.: Unterwegs zu einer "Okologie der Klänge« G. Gr.s »Partiels« und die Ästhetik der Groupe de L'Itinéraire in Musica 42 (1988), Heft 2, 33-55 [mit WV]. WILson, P.N.: Das Lebewesen Klang (Nachruf) in MusikTexte 16 (1998), Heft 76/77, 109. BaILlet, J.: G. Gr., fondements d'une écriture, Paris 2000.

Klaus Schweizer 